\title{
SISTEM PENDUKUNG KEPUTUSAN MURABAHA EMAS ISLAMIC BANK (IB) DENGAN MENERAPKAN METODE ANALYTICAL HIERARCHY PROSES (AHP) (STUDI KASUS: PT BANK BNI SYARIAH MEDAN)
}

\author{
Sari Ramayani ${ }^{1}$
}

${ }^{1}$ Program Studi Teknik Informatika STMIK Budi Darma, Medan, Indonesia

\begin{abstract}
Abstrak
PT Bank BNI Syariah merupakan lembaga keuangan khususnya sector perbankan merupakan instansi masyarakat yang diharapkan mampu memperlancar roda perekonomian suatu Negara.Negara Indoneis sebagai Negara yang mayoritas penduduknya beragama Islam telah lama mendambakan kehadiran system lembaga keuangan yang sesuai tuntutan kebutuhan tidak sebatas financial, namun juga tuntutan moralitasnya.Siste, bank yang di maksud adalah Sistem bak yang terbebas dari praktik bunga yang dinamakan Bank Syariah.Salah satu jenis pembiayaan pada bank syariah terkenal dengan pembiayaan Murabahah yaitu perjanjian jual beli antara bank dengan nasabah. Bank Syariah membeli barang yang diperlukan nasabah kemudian menjualnya kepada nasabah yang bersangkutan sebesar harga perolehan ditambah dengan margin keuntungan yang disepakati antara bank syariah dengan nasabah.salah satu pembiayaan yang berakadkan murabahah ini adalah Murabahah Emas.Metode yang digunakan metode AHP. Analisis statistic yang digunakan untuk mengolah dan menganalisis data serta mengambil simpulan penelitian dari pengujian hipotesis. Dengan Metode AHP diharapkan dapat mempermudah untuk mendapatkan keputusan Murabahah Emas
\end{abstract}

Kata kunci: Pembiayaan Murabahah, Bank Syariah, Efektivitas

\section{Abstract}

PT Bank BNI Syariah is a financial institution, especially the banking sector, a community institution that is expected to be able to smoothen the economy of a country. The Indonesian state as a country whose majority is Muslim has long craved the presence of a financial institution system that suits the demands of the needs not limited to finance, but also demands morality. System, the bank in this case is a system that is free from the practice of interest called Sharia Banks. One type of financing at Islamic banks is known as Murabahah financing, namely a sale and purchase agreement between the bank and the customer. Islamic banks buy goods needed by customers and then sell them to the relevant customers at the acquisition price plus the profit margin agreed between the Islamic bank and the customer. One of the muradaha financing is Murabahah Emas. The method used is the AHP method. Statistical analys is is used to process and analyze data and draw research conclusions from hypothesis testing. The AHP Method is expected to make it easier to get a Golden Murabahah decision

Keywords: Murabahah Financing, Islamic Banks, Effectiveness

\section{PENDAHULUAN}

Murabahah adalah perjanjian jual beli antara bank dengan nasabah.Bank syariah membeli barang yang diperlukan nasabah kemudian menjualnyan kepada nasabah yang bersangkutansebesar harga perolehan ditambah dengan margin keuntungan yang disepakati bank dengan nasabah. Murabahah, dalam konotasi Islam pada dasarnya berarti penjualan. Satu hal yang membedakannya dengan cara penjualan yang lain adalah bahwa penjual dalam murabahah secara jelas memberi tahu kepada pembeli berapa nilai pokok barang tersebut dan berapa besar keuntungan yang dibebankannya pada nilai tersebut. Murabaha Emas adalah pembiayaan emas yang diberikan bank kepada nasabah.

Emas merupakan bentuk investasi yang sangat primadona saat ini. Rully Kustandar menjelaskan manfaat berinvestasi emas, Investasi emas merupakan investasi yang tepat untuk mempertahankan nilai mata uang kita karena emas sifatnya zero Inflation, bahkan jika diperhatikan kenaikan harga emas selalu berbanding lurus dengan laju inflasi.

Dipaparkannya pula, contoh tahun 1997 biaya masuk kuliah masih berkisar 15 juta, namun di 2013 ini biaya masuk kuliah bisa berkisar 50-75jt. Oleh karena itu penting bagi kita untuk mengamankan nilai aset yang kita peroleh dengan kerja keras selama ini agar mempunyai nilai dan daya beli yang sama pada 10 bahkan 20 tahun yang akan datang. Dan emas adalah solusinya. Apalagi untuk memiliki emas dalam hal ini Logam Mulia saat ini sangatlah mudah apalagi bank syariah seperti PT BNI Syariah telah memfasilitasi melalui pembiayaan murabahah emas.

PT Bank BNI Syariah adalah salah satu lembaga keuangan diIndonesia yang berbentuk Bank Umum Syariah yang memberikan jasa keuangan dengan menggunakan prinsip-prinsip perbankan syariah. PT Bank BNI Syariah memberikan bantuan pembiayaan dalam bentuk pembayaran secara kredit/cicilan

dan mempunyai beberapa sistem, prosedur dan persyaratan yang harus dipenuhi oleh calon nasabah.Sehingga sebagai upaya untuk meningkatkan profitabilitas bank syariah maka perlu dilakukan pengelolaan pembiayaan untuk menjaga agar kualitas pembiayaan tetap terjaga dari pembiayaan yang bermasalah serta dari resiko kerugian walaupun pembiayaan emas memiliki resiko kerugian yang kecil dimana emas yang dijadikan jaminan dapat dengan mudah dijual dengan toko emas yang telah bekerja sama terlebih dahulu dengan pihak Bank apabila nasabah tidak sanggup membayar sisa hutangnya. Tetapi demi efisiensi dan efektifitas kerja maka pengambilan keputusan yang tepat sangat diperlukan. Sehingga dalam penentuan kelayakan pemberian pembiayaan kepada calon nasabah PT Bank BNI Syariah terdapat beberapa kriteria yang menjadi penilaian. Penilaian ini berdasarkan analisis kualitatif yakni analisis 5C (character, capital, capacity, condition of economy, collateral).Tujuan dari penelitian ini adalah untuk merancang, mengaplikasikan serta mengembangkan sistem pendukung keputusan (SPK) yang mampu memberikan keputusan kelayakan pembiayaan 
kepada calon nasabah. Metode yang digunakan dalam sistem pendukung keputusan ini adalah metode AHP (Analytical Hierarchy Process).

Pengertian AHP ( Analitycal Hierarchy Process ) AHP merupakan suatu model pendukung keputusan[1]. Model pendukung keputusan ini akan menguraikan masalah multi faktor atau multi kriteria yang kompleks menjadi suatu hirarki, hirarki didefinisikan sebagai suatu representasi dari sebuah permasalahan yang kompleks dalam suatu struktur multi level dimana level pertama adalah tujuan, yang diikuti level faktor, kriteria, sub kriteria, dan seterusnya ke bawah hingga level terakhir dari alternatif. Dengan hirarki, suatu masalah yang kompleks dapat diuraikan ke dalam kelompokkelompoknya yang kemudian diatur menjadi suatu bentuk hirarki sehingga permasalahan akan tampak lebih terstruktur dan sistematis.

\section{TEORITIS}

\subsection{Sistem Pendukung Keputusan}

Sistem pendukung keputusan merupakan sistem informasi interaktif yang menyediakan informasi, pemodelan dan yang pemanipulasi data. Sistem ini digunakan untuk membantu mengambil keputusan dalam situasi yang semi terstruktur dan tak terstruktur, dimana tak seorang pun tahu ssecara pasti bagaimana keputusan seharusnya dibuat [2].

Aplikasi DSS menggunakan data, memberikan antarmuka pengguna yang mudah, dan dapat menggabungkan pemikiran pengambil keputusan. DSS lebih ditujukan untuk mendukung manajemen dalam melakukan pekerjaan yang bersifat analitis dalam situasi yang kurang terstruktur dan dengan kriteria yang kurang jelas. DSS tidak dimaksudkan untuk mengotomatisasikan pengambilan keputusan, tetapi memberikan perangkat interaktif yang memungkinkan pengambil keputusan untuk melakukan berbagai analisis menggunakan model-model yang tersedia.

Sistem pendukung keputusan adalah berbasis komputer sistem informasi yang mengandung bisnis atau organisasi pengambilan keputusan kegiatan. Sistem pendukung keputusan melayani manajemen, operasional, dan tingkat perenanaan organisasi (manajemen biasanya pertengahan dan lebih tinggi) dan membantu untuk membuat keputusan, yang mungkin cepat berubah dan tidak mudah ditentukan dimuka (unstructured dan masalah keputusan semiterstruktur). Sistem pendukung keputusan dapat berupa sepenuhnya terkomputerisasi, manusia atau keduanya. Sementara secara akademis telah dianggap, sistem endukung keputusan sebagai alat untuk mendukung prossess keputusan, pengguna sistem pendukung keputusan melihat pengguna sistem pendukung sebagai alat untuk memfasilitasi proses organisasi.

\subsection{Nasabah}

Nasabah adalah pihak yang menggunakan jasa bank baik bank konvensional maupun bank syariah atau unit usaha syariah. Nasabah pada lembaga perbankan sangat penting. Nasabah itu ibaratnafas yang sangat berpengaruh terhadap suatu bank. Oleh karena itu bank harus dapat menarik nasabah sebanyak-banyaknya agar dana yang terkumpul dari nasabah tersebut dapat disalurkan oleh bank yang nantinya disalurkan kembali kepada masyarakat yang membutuhkan bantuan bank[4].

\subsection{Multi Atribute Decision Making}

Pada dasarnya, proses MADM dilakukan melalui 3 tahap, yaitu penyusunan komponen-komponen situasi, analisis, dan sintesis informasi. Pada tahap penyusunan komponen, komponen situasi, akan dibentuk tabel taksiran yang berisi identifikasi alternatif dan spesifikasi tujuan, kriteria dan atribut. Salah satu cara untuk menspesifikasikan tujuan situasi $\left|\mathrm{O}_{\mathrm{i}}, \mathrm{i}=1, \ldots, \mathrm{t}\right|$ adalah dengan cara mendaftar konsekuensi-konsekuensi yang mungkin dari alternatif yang telah teridentifikasi $\left|\mathrm{A}_{\mathrm{i}}, \mathrm{i}=1, \ldots, \mathrm{n}\right|$. selain itu juga disusun atribut-atribut yang akan digunakan $\left|\mathrm{a}_{\mathrm{k}}, \mathrm{k}=1, \ldots \mathrm{m}\right|$.

Tahapan analisis dilakukan melalui 2 langkah. Pertama, mendatangkan taksiran dari besaran yang potensial, kemungkinan, dan ketidakpastian yang berhubungan dengan dampak-dampak yang mungkin pada setiap alternatif. Kedua, meliputi pemilihan dari preferensi pengambil keputusan untuk setiap nilai, dan ketidakpedulian terhadap resiko yang timbul. Pada langkah pertama, beberapa metode menggunakan fungsi distribusi $\left|\mathrm{p}_{\mathrm{j}}(\mathrm{x})\right|$ yang menyatakan probabilitas kumpulan atribut $\left|\mathrm{a}_{\mathrm{k}}\right|$ terhadap setiap alternatif $\left|\mathrm{A}_{\mathrm{i}}\right|$. konsekuen juga dapat ditentukan secara langsung dari agregasi sederhana yang dilakukan pada informasi terbaik yang tersedia. Demikian pula ada beberapa cara untuk menentukan preferensi pengambilan keputusan pada setiap konsekuen yang dapat dilakukan pada langkah kedua. Metode yang paling sederhana adalah untuk menurunkan bobot atribut dan kriteria adalah dengan fungsi utilitas atau penjumlahan terbobot.

Secara umum, model multi-attribute decision making dapat didefenisikan sebagai berikut :

Misalkan $A=\left\{a_{i} \mid i=1, \ldots n\right\}$ adalah himpunan alternatif-alternatif keputusan dan $C=\left\{c_{j} \mid j=1=1, \ldots, m\right\}$ adalah himpuna tujuan yang diharapkan, maka akan ditentukan alternatif $\chi^{0}$ yang memiliki derajat harapan tertinggi terhadap tujuantujuan yang relevan $\mathrm{c}_{\mathrm{jv}}[5]$.

\subsection{Analitical Hierarchy Process (AHP)}


Secara sederhana, AHP sering diartikan sebagai pembobotan (penentuan prioritas) dari serangkaian persoalan yang dihadapi, baik terhadap kriteria maupun alternatifnya. AHP dapat digunakan untuk memecahkan permasalahan yang kompleks. Adapun Struktur Hirarki AHP dapat digambarkan sebagai berikut[2]:

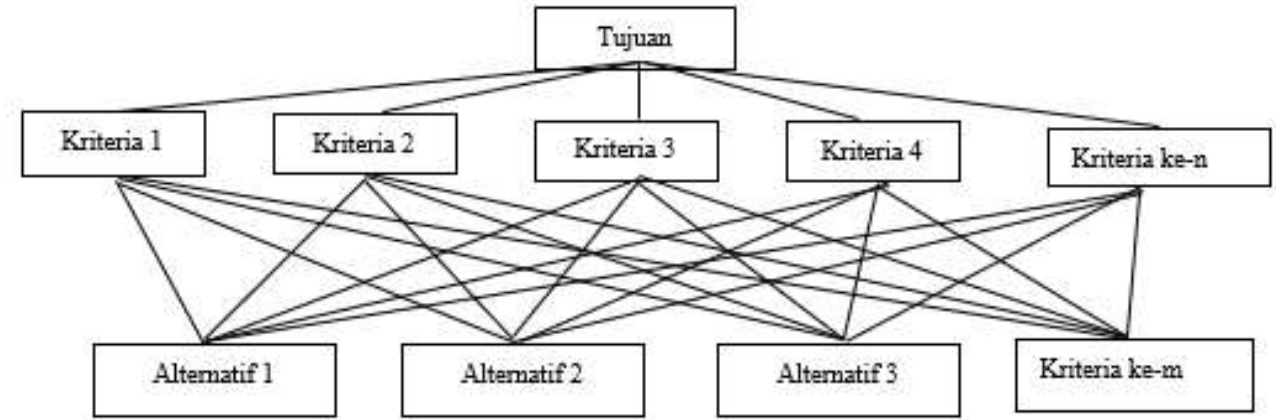

Gambar 1. Struktur Hirarki AHP

Pada dasarnya langkah-langkah dalam metode AHP meliputi[2]:

1. Mendefenisikan masalah dan menentukan solusi yang diinginkan.

2. Menentukan prioritas elemen.

3. Sintesis.

a. Membagi setiap nilai dari kolom dengan total kolom yang bersangkutan untuk memperoleh normalisasi matriks.

b. Menjumlahkan nilai-nilai dari setiap baris dan membaginya dengan jumlah elemen untuk mendapatkan nilai ratarata.

4. Mengukur Konsistensi

Dalam pembuatan keputusan, penting untuk mengetahui seberapa baik konsistensi yang ada karena kita tidak menginginkan keputusan berdasarkan pertimbangan dengan konsistensi yang rendah. Hal yang dilakukan dalam langkah ini adalah :

a. Kalikan setiap nilai pada kolom pertama dengan prioritas relatif elemen pertama, nilai pada kolom kedua dengan prioritas relatif elemen kedua, dan seterusnya.

b. Jumlahkan setiap baris

c. Hasil dari penjumlahan baris dibagi dengan banyaknya elemen yang ada, hasilnya disebut $\lambda$ maks

5. Hitung Consistency Index (CI) dengan rumus :

$\mathrm{CI}=(\lambda$ maks $-\mathrm{n}) / \mathrm{n}$

Dimana $\mathrm{n}=$ banyaknya elemen

6. Hitung Rasio Konsistensi/Consistency Ratio (CR) dengan rumus :

$$
\mathrm{CI}=\mathrm{CI} / \mathrm{RC}
$$

Dimana $\quad \mathrm{CR}=$ Consistency Ratio

$\mathrm{CI}=$ Consistency Index

7. Memeriksa konsistensi hierarki. Jika nilainya lebih dari $10 \%$, maka penilaian data judgment harus diperbaiki. Namun jika rasio konsistensi (CI/IR) kurang atau sama dengan 0,1 maka hasil perhitungan bisa dinyatakan benar.

\section{ANALISA DAN PEMBAHASAN}

Pembiayaan Emas IB Hasanah adalah fasilitas pembiayaan konsumtif yang diberikan kepada masyarakat untuk membeli Emas Logam Mulia sesuai dengan kemampuan masing-masing calon nasabah. Proses Pembiayaan Emas IB Hasanah ini tidaklah sesulit pembiayaan lainnya karena pembiayaan Emas ini memiliki resiko yang cenderung kecil dimana emas yang dibeli dijadikan agunan langsung.Adapun konsep dalam pembiayaan emas ini adalah :

1. Penggunaan

Objek pembiayaan yang dapat diterima adalah Emas Logam Mulia (LM) bersertifikat PT. ANTAM, emas logam mulia (LM) lokal dan koin dinar emas bersertifikat.

2. Bentuk Pembiayaan

Pembiayaan dengan akad Murabaha untuk pembelian emas logam mulia dengan polapembayaran angsuran, objek pembiayaan dibeli dengan harga yang berlaku pada saat akad dan diangsur sebesar nilai angsuran yang bersifat tetap/fixedsetiap bulan sampai dengan waktu jatuh tempo pembiayaan yang disepakati sebelumnya.

3. Maksimum pembiayaan Emas IB Hasanah sebesar Rp 150.000.000 (Seratus Lima Puluh Ribu Rupiah) per nasabah.

\subsection{Penerapan Metode Analytical Hierarchy Process}

Dalam memberikan fasilitas pembiayaan dengan menggunakan metode Analytical Hierarchy Process diperlukan kriteria-kriteria dan bobot untuk melakukan perhitungannya sehingga akan didapat hasil terbaik. 
Untuk mempermudah perhitungan dengan metode Analytical Hierarchy Process setiap alternatif diberikan kode sesuai dengan kode yang sudah ditentukan. Berikut ini adalah data alternatif calon peserta pegawai terbaik yang sudah ditentukan kode nya seperti tertera pada tabel 1.

Tabel 1. Kriteria

\begin{tabular}{|c|c|c|c|c|c|c|}
\hline No & Nama & IntCharacter & I Capacity & CaCapital & Pe Condition & Collateral \\
\hline 1 & A Ary sutanto & 75 & 45 & 40 & 60 & \\
\hline 2 & DrIzki Lubis & 55 & 70 & 33 & 35 & \\
\hline 3 & A Adzkia Samha & 70 & 30 & 60 & 80 & \\
\hline
\end{tabular}

Kriteria yang digunakan didasarkan pada kebutuhan dalam proses pengambilan keputusan, sesuai dengan kriteria yang telah ditentukan dari instansi, adapun kriterianya dapat dilihat pada tabel 2.

Tabel 2. Bobot setiap kriteria

\begin{tabular}{clcc}
\hline No & & Kualitas & Bobot \\
\hline 1 & Character & 2 \\
2 & Capacity & 3 \\
3 & Capital & 1 \\
4 & Condition & 1 \\
5 & Collateral & 3
\end{tabular}

Pada tahap ini adalah proses penilaian terhadap masing-masing alternatif dengan penilaian verbal subkriteria, serperti tabel di bawah ini :

Tabel 3. Penilaian Alternatif

\begin{tabular}{rlllllc}
\hline No & Nama & IntCharacter & I Capacity & BeCapital & Pe Conditon & Cc Collateral \\
\hline 1 & $\begin{array}{l}\text { A Ary } \\
\text { sutanto }\end{array}$ & $75 \mathrm{Kol} 5$ & 454 juta & 40 Gobertap & 6031 thn & $10 \mathrm{gr}$ \\
2 & $\begin{array}{l}\text { DrIzki } \\
\text { Lubis } \\
\text { A Adzkia }\end{array}$ & $55 \mathrm{Kol} \mathrm{3}$ & 702 juta & 33 Wiraswasta & 3537 thn & $5 \mathrm{gr}$ \\
& Samha & 305 juta & 60 Gobertap & 8028 thn & $5 \mathrm{gr}$ \\
\hline
\end{tabular}

Ketentuan datangnya penilaian:

a. Kriteria Slik diberi nilai dengan kolektibilitas terbaik berada pada golongan kolektibilitas 1 .

b. Kriteria DER diberi nilai dengan terbaik dengan penghasilan di atas 3 juta.

c. Kriteria berpenghasilan dengan nilai terbaik golongan berpenghasilan tetap.

d. Kriteria usia dengan nilai terbaik usia diatas 17 tahun.

Apabila $\mathrm{O}_{\mathrm{i}}$ dan $\mathrm{O}_{\mathrm{j}}$ adalah tujuan. Tingkat kepentingan relatif sejumlah tujuan ini dapat dinilai dalam 9 poin seperti tabel 4. berikut;

Tabel 4.4 Tingkat Kepentingan

\begin{tabular}{cl}
\hline Nilai & \multicolumn{1}{c}{ Interpretasi } \\
\hline 1 & $\mathrm{O}_{\mathrm{i}}$ dan $\mathrm{O}_{\mathrm{j}}$ adalah sama penting \\
3 & $\mathrm{O}_{\mathrm{i}}$ tidak lebih penting dari $\mathrm{O}_{\mathrm{j}}$ \\
5 & $\mathrm{O}_{\mathrm{i}}$ lebih penting dari $\mathrm{O}_{\mathrm{j}}$ \\
7 & $\mathrm{O}_{\mathrm{i}}$ sangat lebih penting dari $\mathrm{O}_{\mathrm{j}}$ \\
$1)$ & $\mathrm{O}_{\mathrm{i} \text { mutlak lebih penting dari } \mathrm{O}_{\mathrm{j}}}$ \\
$2,4,6$ & Nilai-nilai intermediate (antara) \\
\hline
\end{tabular}

Maka angka 8 menunjukkan bahwa $\mathrm{O}_{\mathrm{i}}$ delapan kali lebih penting dari pada $\mathrm{O}_{\mathrm{j}}$ atau $\mathrm{O}_{\mathrm{i}}$ terletak antara sangat kuat dan mutlak lebih penting dari pada $\mathrm{O}_{\mathrm{j}}$. Dapat dilihat melalui contoh soal berikut ini :

Misalkan ada 4 alternatif pekerjaan yang akan dipilih, yaitu A, B, C, D dengan mempunyai vector bobot yaitu : W = $0.086,0.130,0.288,0.496, \mathrm{~S}$ (rata-rata), $\mathrm{M}_{\mathrm{B}}$ (matriks baru), $\mathrm{M}_{\mathrm{S}}$ (matriks sebelumnya). Tujuan pertama (lokasi yang baik), matriks perbandingan berpasangan yang ditetapkan adalah:

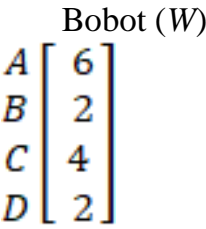

Hasil konsisten; 


\begin{tabular}{|c|c|c|c|c|}
\hline & B & C & $D$ \\
\hline$A$ & 6 & 0.43 & 0.03 & 0.0047 \\
\hline$B$ & 2 & 6 & 0.43 & 0.03 \\
\hline$c$ & 4 & 2 & 6 & 0.43 \\
\hline$D L$ & 2 & 4 & 2 & 6 \\
\hline llh & 14 & 12. & & 6.4 \\
\hline
\end{tabular}

Setelah dilakukan normalisasi, maka:

$\mathrm{M}_{\mathrm{B}}(1.1)=\mathrm{M}_{\mathrm{S}}(1.1) /(14)=0.428, \mathrm{M}_{\mathrm{B}}(1.2)=\mathrm{M}_{\mathrm{S}}(1.2) /(12.43)=0.035, \mathrm{M}_{\mathrm{B}}(1.3)=\mathrm{M}_{\mathrm{S}}(1.3) /(8.46)=0.004, \mathrm{M}_{\mathrm{B}}(1.4)$ $=\mathrm{M}_{\mathrm{S}}(1.4) /(6.464)=6.188$, dan seterusnya dengan cara yang sama maka diperoleh normalisasi matriks.

$$
\text { A } \quad B \quad \text { C } \quad D \quad \text { Rata-rata }
$$

$A$
$B$
$C$
$D$$\left[\begin{array}{cccc}0.428 & 0.035 & 0.004 & 6.188 \\ 0.143 & 0483 & 0.43 & 0.005 \\ 0.143 & 0.161 & 0.709 & 0.067 \\ 0.322 & 0.236 & 1.344\end{array}\right] \begin{aligned} & 1.664 \\ & 0.171 \\ & 0.306 \\ & 0.511\end{aligned}$

Sehingga: $S_{11}=1.664, S_{12}=0.171, S_{13}=0.306, S_{14}=0.511$

Pada tujuan ke dua (nilai kriteria), matriks perbandingan berpasangan yang ditetapkan adalah:

$$
\begin{array}{lllll}
A & B & C & D
\end{array}
$$

$A$
$B$
$C$$\left[\begin{array}{cccc}0.428 & 0.035 & 0.004 & 6.188 \\ 0.143 & 0483 & 0.43 & 0.005 \\ 0.286 & 0.161 & 0.709 & 0.067 \\ 0.143 & 0.322 & 0.236 & 1.344\end{array}\right]$

\section{$\begin{array}{lllll}\text { flh } & 1 & 1.001 & 1 & 7.604\end{array}$}

Setelah dilakukan normalisasi, maka:

$\mathrm{M}_{\mathrm{B}}(1.1)=\mathrm{M}_{\mathrm{S}}(1.1) /(1)=0.428, \mathrm{M}_{\mathrm{B}}(1.2)=\mathrm{M}_{\mathrm{S}}(1.2) /(1.001)=0.035, \mathrm{M}_{\mathrm{B}}(1.3)=\mathrm{M}_{\mathrm{S}}(1.3) /(1)=0.004, \mathrm{M}_{\mathrm{B}}(1.4)=$ $\mathrm{M}_{\mathrm{S}}(1.4) /(7.604)=0.814$, dan seterusnya dengan cara yang sama maka diperoleh normalisasi matriks :

$\begin{array}{ccccc}A & B & C & D & \text { Rata-rata } \\ A \\ B \\ C \\ D\end{array}\left[\begin{array}{cccc}0.428 & 0.035 & 0.004 & 0.814 \\ 0.143 & 0483 & 0.051 & 6.575 \\ 0.286 & 0.161 & 0.709 & 0.009 \\ 0.143 & 0.322 & 0.236 & 0.177\end{array}\right] \quad \begin{aligned} & 0.321 \\ & 0.291 \\ & 0.219\end{aligned}$

Sehingga: $\mathrm{S}_{21}=0.321 ; \mathrm{S}_{22}=1.813 ; \mathrm{S}_{23}=0.291$

Pada tujuan ke tiga (penjumlahan setiap kolom), matriks perbandingan berpasangan yang ditetapkan adalah :

$$
\begin{array}{llll}
A & B & C & D
\end{array}
$$

$A$
$B$
$C$$\left[\begin{array}{cccc}0.428 & 0.035 & 0.004 & 0.814 \\ 0.143 & 0483 & 0.43 & 6.575 \\ 0.286 & 0.161 & 0.709 & 0.009 \\ 0.143 & 0.322 & 0.236 & 0.177\end{array}\right]$

$\begin{array}{lllll}\text { llh } & 1 & 1.001 & 1 & 7.575\end{array}$

Setelah dilakukan normalisasi, maka: 
$\mathrm{M}_{\mathrm{B}}(1.1)=\mathrm{M}_{\mathrm{S}}(1.1) /(1)=0.428, \mathrm{M}_{\mathrm{B}}(1.2)=\mathrm{M}_{\mathrm{S}}(1.2) /(1.001)=0.035, \mathrm{M}_{\mathrm{B}}(1.3)=\mathrm{M}_{\mathrm{S}}(1.3) /(1)=0.004, \mathrm{M}_{\mathrm{B}}(1.4)=$ $\mathrm{M}_{\mathrm{S}}(1.4) /(7.575)=0.107$, dan seterusnya dengan cara yang sama maka diperoleh normalisasi matriks :

\begin{tabular}{|c|c|c|c|c|c|}
\hline A & & C & $D$ & \multicolumn{2}{|c|}{ Rata-rata } \\
\hline & 0.428 & 0.035 & 0.004 & $0.107]$ & 0.574 \\
\hline & 0.143 & 0483 & 0.051 & 0.868 & 0.386 \\
\hline & 0.286 & 0.161 & 0.709 & 0.001 & 0.289 \\
\hline & 0.143 & 0.322 & 0.236 & 0.023 & 0.181 \\
\hline
\end{tabular}

Sehingga $\mathrm{S}_{31}=0.574 ; \mathrm{S}_{32}=0.386 ; \mathrm{S}_{33}=0.289 ; \mathrm{S}_{34}=0.181$

Pada tujuan ke empat (perhitungan rasio konsistensi), matriks perbandingan berpasangan yang ditetapkan adalah:

$\left.\begin{array}{c}A \\ A\end{array}\right] \begin{array}{cccc}0.428 & 0.035 & 0.004 & 0.107 \\ B \\ C \\ D\end{array}\left[\begin{array}{llll}0.143 & 0.483 & 0.051 & 0.868 \\ 0.286 & 0.161 & 0.709 & 0.001 \\ 0.143 & 0.322 & 0.236 & 0.023\end{array}\right]$

\section{$\begin{array}{lllll}\text { flh } & 1 & 1.001 & 1 & 0.999\end{array}$}

$\mathrm{M}_{\mathrm{B}}(1.1)=\mathrm{M}_{\mathrm{S}}(1.1) /(1)=0.428, \mathrm{M}_{\mathrm{B}}(1.2)=\mathrm{M}_{\mathrm{S}}(1.2) /(1.001)=0.035, \mathrm{M}_{\mathrm{B}}(1.3)=\mathrm{M}_{\mathrm{S}}(1.3) /(1)=0.004, \mathrm{M}_{\mathrm{B}}(1.4)=$ $\mathrm{M}_{\mathrm{S}}(1.4) /(0.999)=0.107$, dan seterusnya dengan cara yang sama maka diperoleh normalisasi matriks :
A
B
C
D
Rata-rata

$A$
$B$
$C$
$D$$\left[\begin{array}{ll}0.428 & 0.035 \\ 0.143 & 0483 \\ 0.286 & 0.161 \\ 0.143 & 0.322\end{array}\right.$

\subsection{5}

0.004

$0.107] \quad 0.574$

0.051

0.869

0.387

$\begin{array}{ll}0.709 & 0.001\end{array}$

0.289

Sehingga: $\mathrm{S}_{41}=0.574 ; \mathrm{S}_{42}=0.386 ; \mathrm{S}_{43}=0.289 ; \mathrm{S}_{44}=0.181$

Matriks sekor alternatif pada semua tujuan, diperoleh dari nilai rata-rata pada setiap matriks, maka diperoleh matriks:

$\left.\begin{array}{c}A \\ A\end{array}\right] \begin{array}{cccc}1.664 & 0.171 & 0.306 & 0.511 \\ B \\ C \\ D\end{array}\left[\begin{array}{llll}0.321 & 1.813 & 0.291 & 0.219 \\ 0.574 & 0.386 & 0.289 & 0.181 \\ 0.574 & 0.387 & 0.289 & 0.181\end{array}\right]$

Vektor bobot yang telah diketahui adalah:

$\mathrm{W}=[0.086 ; 0.130 ; 0.288 ; 0.496]$

Maka hasil skor total untuk setiap alternatif adalah:

$\mathrm{S}_{1}=(1.664)(0.086)+(0.321)(0.130)+(0.574)(0.288)+(0.574)(0.496)=0.635$

$\mathrm{S}_{2}=(0.171)(0.086)+(1.813)(0.130)+(0.386)(0.288)+(0.387)(0.496)=0.544$

$S_{3}=(0.306)(0.086)+(0.291)(0.130)+(0.289)(0.288)+(0.289)(0.496)=0.29$

$\mathrm{S}_{4}=(0.511)(0.086)+(0.219)(0.130)+(0.181)(0.288)+(0.181)(0.496)=0.089$

Kesimpulan: Karena skor total alternatif A $\left(S_{1}\right)$ paling besar, maka alternatif A yang paling dipilih.

\section{KESIMPULAN}

Berdasarkan perumusan masalah dan pembahasan pada bab-bab sebelumnya maka dapat diambil kesimpulan sebagai berikut :

1. Prosedur pemilihan nasabah yang dapat diberikan pembiayaan dilakukan dengan proses penilaian menggunakan aspek-aspek penilaian seperti Character, Capacity, Capital, Collateral, dan Condition. agar bisa diperoleh nasabah yang sesuai dengan criteria yang ditetapka oleh BNI syariah Kantor Cabang Medan

2. Proses pemilihan Nasabah yang dilakukan melalui perhitungan dengan metode Analytical Hierarchy Process (AHP) dimulai dengan pemberian nilai kriteria untuk masing-masing kriteria, Alternatif, pembobotan, perhitungan indeks preferensi, dan perhitungan arah preferensi sehingga menghasilkan nilai dari masing- masing kriteria. 
3. Sistem Pendukung Keptusan Pemilihan Nasabah untuk diberikan pembiayaan dengan menggunakan bahasa pemrograman PHP dan Mysql.

4. Metode AHP dapat diterapkan untuk mengambil keputusan pemberian pembiayaan Murabahah Emas.

\section{REFERENCES}

[1] S. Kusumadewi, S. Hartati, A. Harjoko, and Retantyo Wardoyo, "Fuzzy Multi Attribute Decision Making (FUZZY MADM)," Ed. Pertama Cetakan Pertama. Graha Ilmu. Yogyakarta., 2006.

[2] Kusrini, Sistem Pendukung Keputusan dan Aplikasinya. Yogyakarta: Andi, 2007.

[3] H. Susanto, "Penerapan Metode Additive Ratio Assessment ( Aras ) Dalam Pendukung Keputusan Pemilihan Susu Gym," Maj. Ilm. INTI, vol. 13, pp. 1-5, 2018

[4] N. A. H. Tetty Rosmaria Sitompul, "SISTEM PENDUKUNG KEPUTUSAN SELEKSI TENAGA KERJA UNTUK SECURITY SERVICE MENGGUNAKAN METODE ARAS,” vol. 2, no. 1, pp. 1-9, 2018.

[5] M. A. Hasmi, B. Nadeak, N. Sitompul, and M. Mesran, "SISTEM PENDUKUNG KEPUTUSAN PENERIMAAN INSTRUKTUR FITNESS MENERAPKAN METODE ADDITIVE RATIO ASSESSMENT ( ARAS ) ( STUDI KASUS : VIZTA GYM MEDAN )," KOMIK (Konferensi Nas. Teknol. Inf. dan Komputer), vol. 2, no. 2010, pp. 121-129, 2018.

[6] E. K. Zavadskas and Z. Turskis, "A new additive ratio assessment ( ARAS ) method in multicriteria decision - making," vol. 8619, 2011.

[7] Esra; and AyG̣egül, “AIR CONDITIONER SELECTION PROBLEM WITH COPRAS AND ARAS METHODS,” Manas J. Soc. Stud., vol. 5, no. 2, 2016.

[8] F. Pratiwi, F. T. Waruwu, D. P. Utomo and R. Syahputra, "Penerapan Metode Aras Dalam Pemilihan Asisten Perkebunan Terbaik Pada PTPN V," Seminar Nasional Teknologi Komputer \& Sains (SAINTEKS), pp. 651-662, 2019. 